\title{
Clear cell borderline tumor without fibromatous component: Pathological and literature review and report of two cases
}

\author{
TAIRA HADA ${ }^{1}$, MORIKAZU MIYAMOTO $^{1}$, HIROKI ISHIBASHI $^{1}$, HIROKO MATSUURA $^{1}$, \\ TAKAHIRO SAKAMOTO ${ }^{1}$, SOICHIRO KAKIMOTO ${ }^{1}$, HIDEKI IWAHASHI ${ }^{1}$, \\ RIE SUZUKI ${ }^{1}$, HITOSHI TSUDA ${ }^{2}$ and MASASHI TAKANO ${ }^{1}$ \\ Departments of ${ }^{1}$ Obstetrics and Gynecology and ${ }^{2}$ Pathology, \\ National Defense Medical College Hospital, Tokorozawa, Saitama 359-8513, Japan
}

Received April 21, 2020; Accepted January 21, 2021

DOI: $10.3892 / \mathrm{mco} .2021 .2237$

\begin{abstract}
The aim of the present study was to examine the clinical outcome of ovarian clear cell borderline tumor (CCBT) through pathological review for cases with clear cell carcinoma (CCC) and CCBT between 1984 and 2015 who received surgery at the National Defense Medical College Hospital using 2020 World Health Organization (WHO) criteria. In addition to the definition of CCBT in 2020 WHO criteria, clear cell with atypia of the glandular epithelium without fibromatous component was added to the diagnostic criteria of CCBT. Two cases with CCBT were identified through review in the current study. There were no cases that changed from the initial CCBT diagnosis that were included in the current study. Case 1 was a 43-year-old woman who received total hysterectomy, bilateral salpingo-oophorectomy and partial omentectomy. Pathologically, cysts were lined by cuboidal, hobnail and clear cells with eosinophilic cytoplasm and moderate nuclear atypia without the fibromatous component. These cells were adjacent to atypical endometriosis and non-atypical endometriosis, and the patient was diagnosed with CCBT. She exhibited no evidence of the disease for 37 months following surgery. Case 2 was a 42-year-old woman who received left salpingo-oophorectomy, partial omentectomy and pelvic lymphadenectomy. The tumor exhibited a cyst $(80 \mathrm{~mm})$ and nodular component. Pathologically, the tumor cells were lined
\end{abstract}

Correspondence to: Dr Morikazu Miyamoto, Department of Obstetrics and Gynecology, National Defense Medical College Hospital, 3-2 Namiki, Tokorozawa, Saitama 359-8513, Japan E-mail: morikazu1118@hotmail.co.jp

Abbreviations: OBT, ovarian borderline tumors; FIGO, International Federation of Gynecology and Obstetrics; WHO, World Health Organization; CCBT, clear cell borderline tumor; $\mathrm{CCC}$, clear cell carcinoma; HE, hematoxylin and eosin; IHC, immunohistochemistry; HNF1- $\beta$, hepatocyte nuclear factor 1 beta; WT1, Wilms' tumor 1; CA125, carbohydrate antigen 125; CA19-9, carbohydrate antigen 9-9

Key words: clear cell borderline tumor, ovarian borderline tumor by hobnail cells with mild atypia and eosinophilic cytoplasm without the fibromatous component. This patient was diagnosed with CCBT and exhibited no evidence of disease for 20 months following surgery. CCBT without fibromatous component is a rare and non-aggressive histological subtype. Additionally, regardless of fibromatous component, CCBT was able to be diagnosed.

\section{Introduction}

Ovarian borderline tumors (OBT) have firstly been reported as the entity of ovarian tumors by Taylor in 1929 (1). After then, OBT was recognized by the International Federation of Gynecology and Obstetrics (FIGO) in 1971 and the World Health Organization (WHO) in 1973 (2,3). Briefly, histological feature of OBT was the presence of slight nuclear atypia or cellular proliferation, with or without microinvasion defined as small foci of stromal invasion measuring $<5 \mathrm{~mm}$ in greatest linear extent (4). Its 10 -year survival was $99 \%$ for FIGO stage I, $98 \%$ for stage II, $96 \%$ for stage III, and $77 \%$ for stage IV, respectively (5). The term of OBT has been changed during decades, but the concept has been adopted to 2020 WHO criteria (6).

In histological subtypes of OBT, the major types were serous (50\%) and mucinous (45\%) borderline tumor. Endometrioid, clear cell, and seromucinous borderline tumor, and borderline Brenner tumor were the minor types $(4,7)$. According to $2020 \mathrm{WHO}$ criteria, the frequency of clear cell borderline tumor (CCBT) was $<1 \%$ of OBT and was defined as an adenofibromatous clear cell tumors with glandular crowding and low-grade nuclear atypia without stromal invasion (6). Hence, Suzuki et al reported CCBT without fibromatous component (8). However, due to the rarity, the clinical outcome was unclear because CCBT, particularly, without fibromatous component was rare.

Herein, the aim of our study was to explore CCBT through pathological review for cases diagnosed with CCBT and clear cell carcinoma (CCC) and review literature about CCBT with and without fibromatous component.

\section{Materials and methods}

Patients, pathological review and definition. Patients with ovarian CCBT or CCC treated with surgery at our hospital 
between 1984 and 2015 were identified. We excluded patients which had no medical records and hematoxylin and eosin (HE) slide. Pathological review for all patients using the definition of $2020 \mathrm{WHO}$ criteria and the previous report by Lokuhetty et al and Suzuki et al $(6,8)$. Briefly, the definition of CCBT was that tumors characterized by glands lined by cubic or flat cells with enlarged nuclei, clear or eosinophilic cytoplasm, low mitotic activity, and sometimes nucleoli, with or without fibromatous component. Also, the definition of CCC was that tumors composed of clear, eosinophilic, and hobnail cells, with tubulocystic, papillary, and solid architecture.

Immunohistochemistry (IHC) staining and interpretation of IHC staining. For IHC staining, we used rabbit monoclonal antibody for hepatocyte nuclear factor 1 beta (HNF1- $\beta$ ) (EPR18644-13; dilution 1:2,000; Abcam), mouse monoclonal antibody for p53 (DO7, dilution 1:50; Dako), mouse monoclonal antibody for Wilms' tumor 1 (WT1) (6F-H2; dilution 1:50; Dako), and mouse monoclonal antibody for Ki-67 (M7240; dilution 1:50; Dako). All specimens were cut into $4 \mu \mathrm{m}$ thick slices to make tissue sections for IHC staining. The tissue sections were deparaffinized in xylene and hydrated with alcohol. Endogenous peroxidase activity was blocked using methanol added to $0.3 \%$ hydrogen peroxidase. The tissue sections were boiled at $98^{\circ} \mathrm{C}$ for $40 \mathrm{~min}$ in Tris/EDTA buffer ( $\mathrm{pH}$ 9.0) using HNF-1 $\beta$ and in an autoclave at $121^{\circ} \mathrm{C}$ for $15 \mathrm{~min}$ in citrate buffer $(\mathrm{pH}$ 6.0) using $\mathrm{p} 53$, WT-1, and $\mathrm{Ki}-67$, and were then allowed to cool at room temperature. The slides were incubated at $4^{\circ} \mathrm{C}$ overnight with primary antibodies. Following incubation, the samples were reacted with the DAKO EnVision + system-HRP labeled polymer as secondary antibody for $30 \mathrm{~min}$ at room temperature. Specific antigen-antibody reactions were visualized with $0.2 \%$ diaminobenzidine tetrahydrochloride and hydrogen peroxide, and counterstained with Mayer's hematoxylin. As negative controls, tissue sections without the primary antibody were used. For the evaluation of IHC activities of HNF1- $\beta$, p53, WT1, and Ki-67, the presence of nuclear immunoreaction in $>10 \%$ of all tumor cells was defined as positive.

Medical and surgical data, stage and ethics approval. Medical and surgical data were obtained from the medical and surgical records. All cases were staged according to the 2014 International Federation of Gynecology and Obstetrics (FIGO) staging system (9). This study was approved by the Ethics Committee of the National Defense Medical College, Tokorozawa, Japan.

\section{Results}

Results of pathological review. During study period, 136 cases with CCC and 2 cases with CCBT were identified. Through pathological review, Among 136 cases with CCC, 126 cases were diagnosed with CCC, 10 cases with other histological subtypes, and there were no cases with CCBT (Table I). Among 126 cases with CCC, median age was 53.4 and 76 cases $(60.3 \%)$ were diagnosed with FIGO stage I, 17 cases (13.5\%) with FIGO stage II, 30 cases $(23.8 \%)$ with FIGO stage III, and 3 cases $(2.4 \%)$ with FIGO stage IV. Endometriosis was
Table I. Characteristics of two cases with clear cell borderline tumor and 126 cases with clear cell carcinoma.

\begin{tabular}{|c|c|c|}
\hline Variables & $\begin{array}{l}\text { Clear cell } \\
\text { borderline } \\
\text { tumor } \\
(n=2)\end{array}$ & $\begin{array}{l}\text { Clear cell } \\
\text { carcinoma } \\
(\mathrm{n}=126)\end{array}$ \\
\hline \multicolumn{3}{|l|}{ Age (years) } \\
\hline Median \pm SD & - & $53.4 \pm 9.4$ \\
\hline \multicolumn{3}{|l|}{ FIGO stage $(\%)$} \\
\hline I & $2(100.0)$ & $76(60.3)$ \\
\hline II & $0 \quad(0.0)$ & $17(13.5)$ \\
\hline III & $0 \quad(0.0)$ & $30(23.8)$ \\
\hline IV & $0 \quad(0.0)$ & $3(2.4)$ \\
\hline \multicolumn{3}{|l|}{ Endometriosis (\%) } \\
\hline Yes & $2(100.0)$ & $58(46.0)$ \\
\hline No & $0 \quad(0.0)$ & $68(54.0)$ \\
\hline \multicolumn{3}{|l|}{ Peritoneal cytology (\%) } \\
\hline Positive & $0 \quad(0.0)$ & $73(57.9)$ \\
\hline Negative & $2(100.0)$ & $53(42.1)$ \\
\hline \multicolumn{3}{|l|}{$\begin{array}{l}\text { Residual tumor at primary } \\
\text { surgery }(\%)\end{array}$} \\
\hline Yes & $0 \quad(0.0)$ & $28(22.2)$ \\
\hline No & $2(100.0)$ & $98(77.8)$ \\
\hline \multicolumn{3}{|l|}{ Adjuvant chemotherapy $(\%)$} \\
\hline Taxane-platinum therapy & $0 \quad(0.0)$ & $33(26.2)$ \\
\hline Platinum-based therapy & $0 \quad(0.0)$ & $87(69.1)$ \\
\hline Not administered & $2(100.0)$ & $6 \quad(4.7)$ \\
\hline \multicolumn{3}{|l|}{ Response rate $(\%)$} \\
\hline $\mathrm{CR} / \mathrm{PR}$ & N/A & $12(42.9)$ \\
\hline $\mathrm{SD} / \mathrm{PD}$ & N/A & $16(57.1)$ \\
\hline
\end{tabular}

$\mathrm{CR}$, complete response; PR, partial response; $\mathrm{SD}$, stable disease; $\mathrm{PD}$, progressive disease.

observed in 58 cases (46.0\%). Seventy-three cases $(57.9 \%)$ had Positive peritoneal cytology, and 28 cases (22.2\%) had residual tumor at primary surgery. Conventional chemotherapy was performed for 120 cases $(95.3 \%)$. Among cases with evaluable diseases, 12 cases $(42.9 \%)$ were complete response or partial response to conventional chemotherapy. Two cases were diagnosed with CCBT. The initial diagnosis of these 2 cases were CCBT.

Case 1. A 43-year-old woman, gravida 0, para 0, with no symptom was referred to our hospital for ovarian tumor. She had no surgical, medical, and specific family history. Serum tumor markers did not elevate: $9.2 \mathrm{U} / \mathrm{ml}$ of carbohydrate antigen 25 (CA125) and $6.8 \mathrm{U} / \mathrm{ml}$ of carbohydrate antigen 9-9 (CA19-9). Magnetic resonance imaging (MRI) showed that multilocular ovarian cyst with a size of $86 \times 50 \times 65 \mathrm{~mm}$ had a solid part with a weak Gadolinium enhancement in low signal area in T2-weighted images. Computer tomography (CT) images did not reveal no metastasis. The endometrial and cervical 

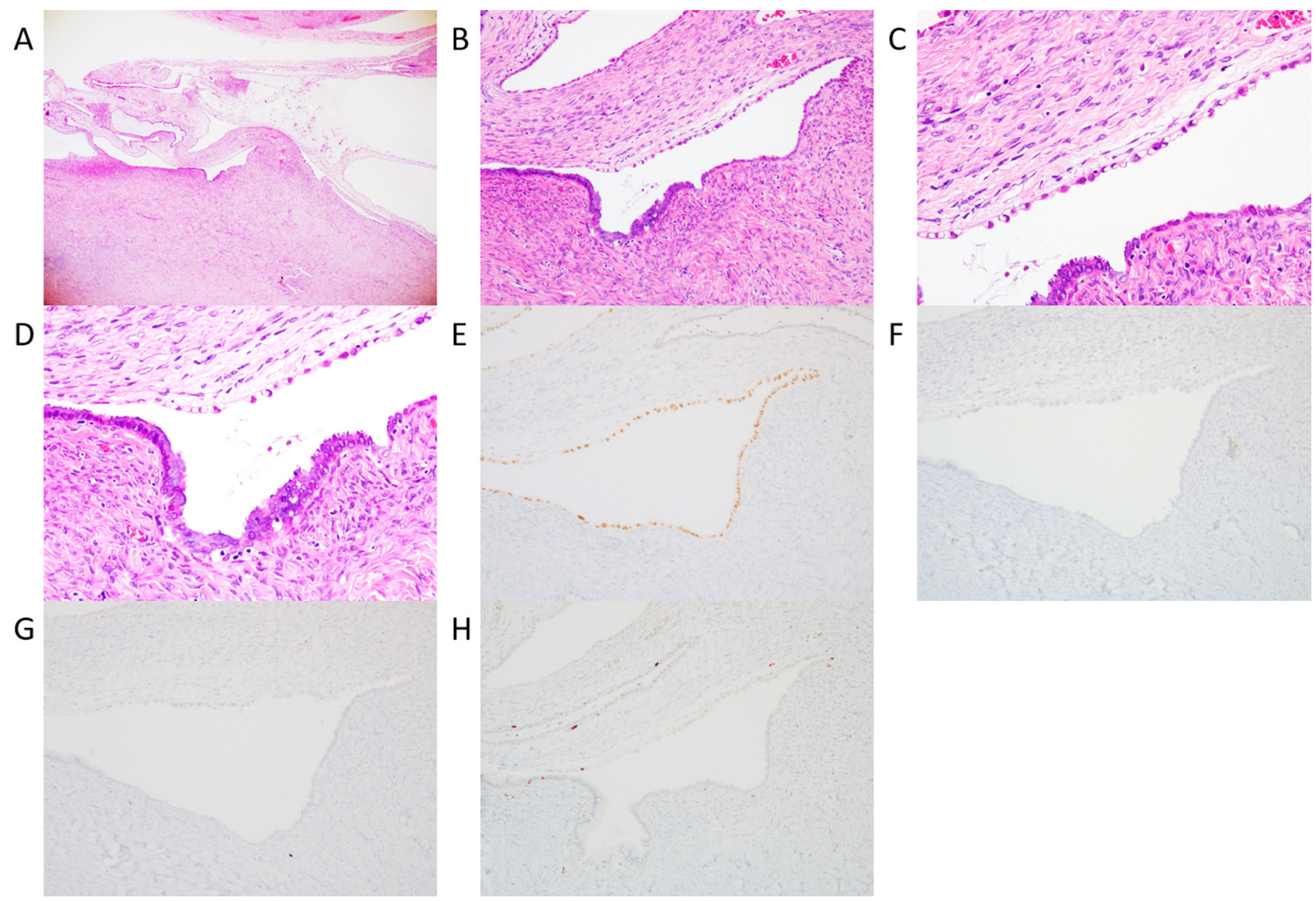

Figure 1. Histological and immunohistochemical images of CCBT in case 1. (A) Tumor was consisted of multilocular cysts (magnification, x40). (B) Cyst was lined by epithelium cells which showed a transition from CCBT to atypical endometriosis (magnification, x200). (C) Part of the epithelium cells showed clear cells and hobnail cells with mild to moderate nuclear atypia (magnification, $\mathrm{x} 400$ ). (D) Some of the cells showed atypical endometriosis (magnification, $\mathrm{x} 400$ ). (E) The expression of hepatocyte nuclear factor $1 \beta$ was detected in the monolayered lining cells (magnification, x200). (F) p53-negative cells were lined in the lining cells (magnification, x200). (G) Wilms' tumor 1-negative cells were lined in the lining cells (magnification, x200). (H) The expression of Ki-67 was partially detected but by $<10 \%$ in the monolayered lining cells (magnification, x200). CCBT, clear cell borderline tumor.

cytology could not detect malignant cell. The preoperative diagnosis suspected OBT. She received total hysterectomy, bilateral salpingo-oophorectomy and partial omentectomy because operative rapid pathological diagnosis showed borderline ovarian tumor. In the pelvic cavity, the uterus and bilateral ovaries did not adhere to the other pelvic organs. The ovarian tumor was unruptured. Ascites was not observed. Macroscopically, the left ovary had multiple cysts with a size of 20x40 mm. Pathologically, cysts were lined by cuboidal and hobnail cells with clear and eosinophilic cytoplasm (Fig. 1A-D). The lining cells showed moderate nuclear atypia without microinvasion and fibromatous component. CCBT was adjacent to atypical endometriosis. In IHC analysis, almost all CCBT cells was positive for HNF-1 $\beta$ (Fig. 1E), and negative for p53 (Fig. 1F) and WT-1 (Fig. 1G). They were partially positive for Ki-67 $(<10 \%$, Fig. 1H). She was diagnosed with CCBT without fibromatous component. She did not receive any adjuvant therapy and lived with no evidence of disease for 37 months from surgery.

Case 2. A 42-year-old woman, gravida 3, para 3, presented with no symptom. She had no surgical, medical, and specific family history. Serum tumor markers did not elevate: 26.2 U/ml of CA125 and $33.7 \mathrm{U} / \mathrm{ml}$ of CA19-9. Transvaginal ultrasonography revealed unilocular cyst with a size of $\sim 8 \mathrm{~cm}$. MRI demonstrated that unilocular ovarian cyst with the size of $80 \mathrm{~mm}$ had scattered solid part with a weak Gadolinium enhancement in low signal area in T2-weighted images. CT images did not reveal no metastasis. The endometrial and cervical cytology did not enable us to detect malignant cells. The preoperative diagnosis suspected OBT. The patient underwent left salpingo-oophorectomy, partial omentectomy, and pelvic lymphadenectomy because operative rapid pathological diagnosis revealed serous or mucinous borderline tumor. In the pelvic cavity, the left ovary adhered to the uterus. The ovarian tumor was unruptured. There was a little amount of ascites. Macroscopically, the left ovary was a cyst with the size of 76x67 $\times 42 \mathrm{~mm}$ and nodule component was observed in the cyst. Pathologically, nodule component was lined by increasing calcified spindle cells without atypia. The tumor cells were lined by hobnail cells with mild nuclear atypia and eosinophilic cytoplasm without microinvasion, fibromatous component, and endometriosis (Fig. 2A and B). In IHC analysis, almost all CCBT cells were positive for HNF-1 $\beta$ (Fig. 2C), negative for p53 (Fig. 2D), WT-1 (Fig. 2E), and Ki-67 (Fig. 2F). She was diagnosed with CCBT without fibromatous component and lived with no evidence of disease after the surgery for 20 months. 

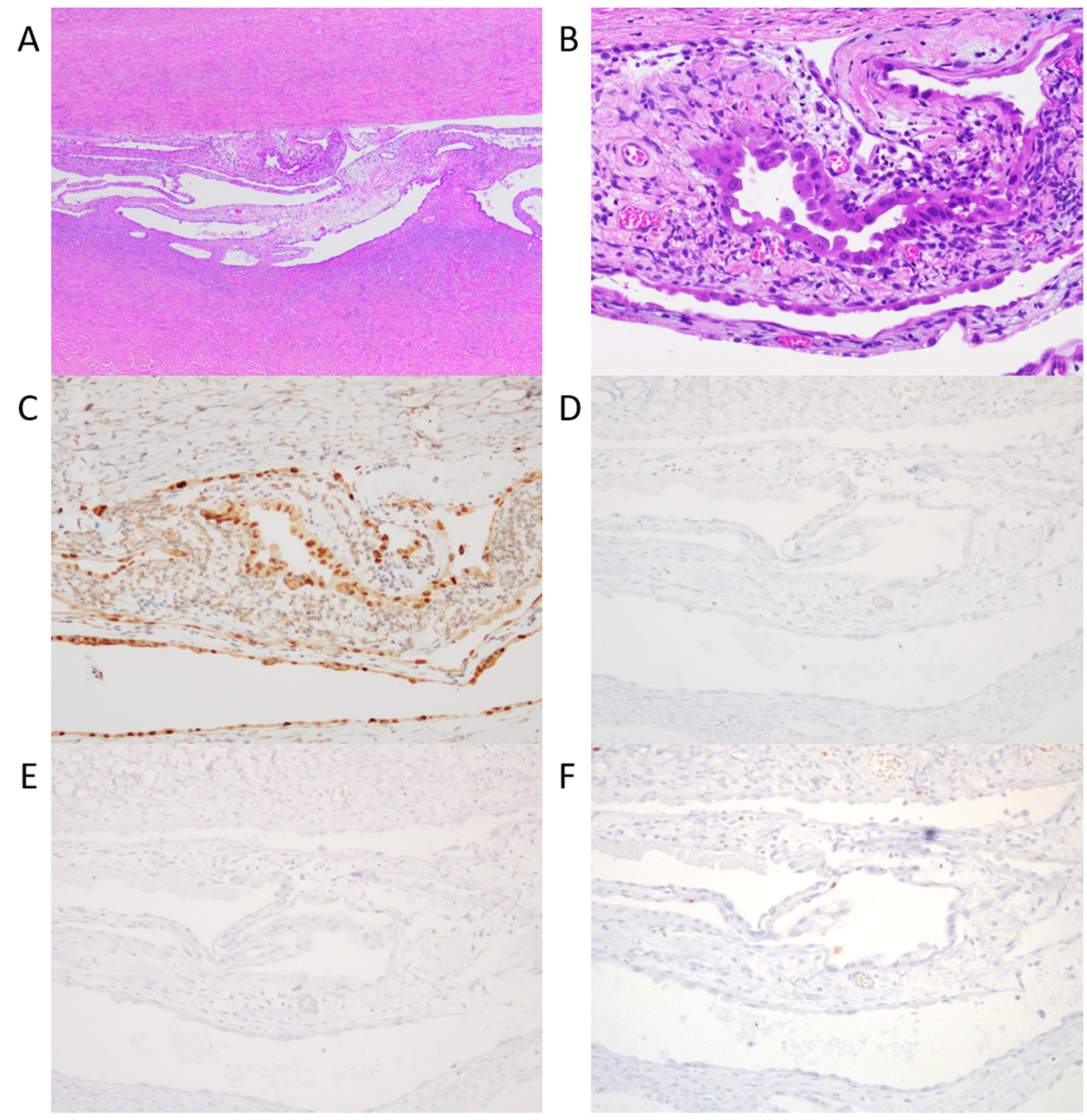

Figure 2. Histological and immunohistochemical images of CCBT in case 2. (A) Tumor was consisted of multilocular cysts. Most of the epithelium lining the tumor was made of flattened, or cuboidal cells with mild to moderate atypia. (magnification, x40). (B) Cyst was lined by hobnail cells with mild to moderate nuclear atypia (magnification, x200). (C) The expression of hepatocyte nuclear factor $1 \beta$ was detected in the monolayered lining cells (magnification, x200). (D) p53-negative cells were lined in the lining cells (magnification, x200). (E) Wilms' tumor 1-negative cells were lined in the lining cells (magnification, x200). (F) The expression of Ki-67 was partially detected but by $<10 \%$ in the monolayered lining cells (magnification, x200). CCBT, clear cell borderline tumor.

\section{Discussion}

In our study, we reviewed 136 cases with CCC and 2 cases with CCBT, and found 2 cases with CCBT through review. There was no fibromatous component in both cases with CCBT, and 1 of them had endometriosis component which showed a continuum of differentiation to CCBT component.

CCBT was reported to be rare and difficult to diagnose (10). The discriminating histological findings between CCBT and CCC was nuclear grading. CCBT was characterized by an intermediate nuclear grade, while CCC was characterized by at least focal high-grade nuclear atypia with prominent nucleoli. However, nuclear grading was highly subjective and that should err on the side of malignancy (11). Also, when CCBT was complicated with serous borderline tumor or seromucinous borderline tumors, the diagnosis was difficult. This complication was frequently observed $(12,13)$. Then, immunochemical study was helpful and CCBT was negative for WT-1 and p53 and positive for HNF-1 $\beta(14,15)$. In our study, no case with CCC was diagnosed with CCBT and the diagnosis between CCBT and CCC was not difficult. Also, immunochemical analysis confirmed 2 cases with
CCBT were immunohistochemically positive for HNF-1 $\beta$, and negative for $\mathrm{p} 53$ and WT-1. Therefore, our cases were not complicated with other OBT and was diagnosed with pure-type CCBT.

A review of literature of CCBT with and without fibromatous component including our study were demonstrated in Table II $(8,16-26)$. There were 81 cases with CCBT; 77 cases (95.1\%) with fibromatous component and 4 cases (4.9\%) without fibromatous component. About cases with CCBT with fibromatous component, age ranged from 30 to 86 years, all cases were diagnosed with FIGO stage I, and 4 cases (5.2\%) had tumors in bilateral ovaries. 2 cases $(2.6 \%)$ suffered from recurrence, but no case died of the disease. On contrast, about cases with CCBT without fibromatous component, age ranged from 42 to 76 years, all cases were diagnosed with FIGO stage I, and no cases had tumors in bilateral ovaries. No case recurred or died of disease. Comparing these two groups, the presence or absence of fibromatous component in CCBT might not be related to their clinicopathological features.

Past report proposed the pathogenesis of CCBT and CCC with 2 developing pathways; endometriotic cystic pathway and adenofibromatous pathway (22). In the endometriotic cystic 


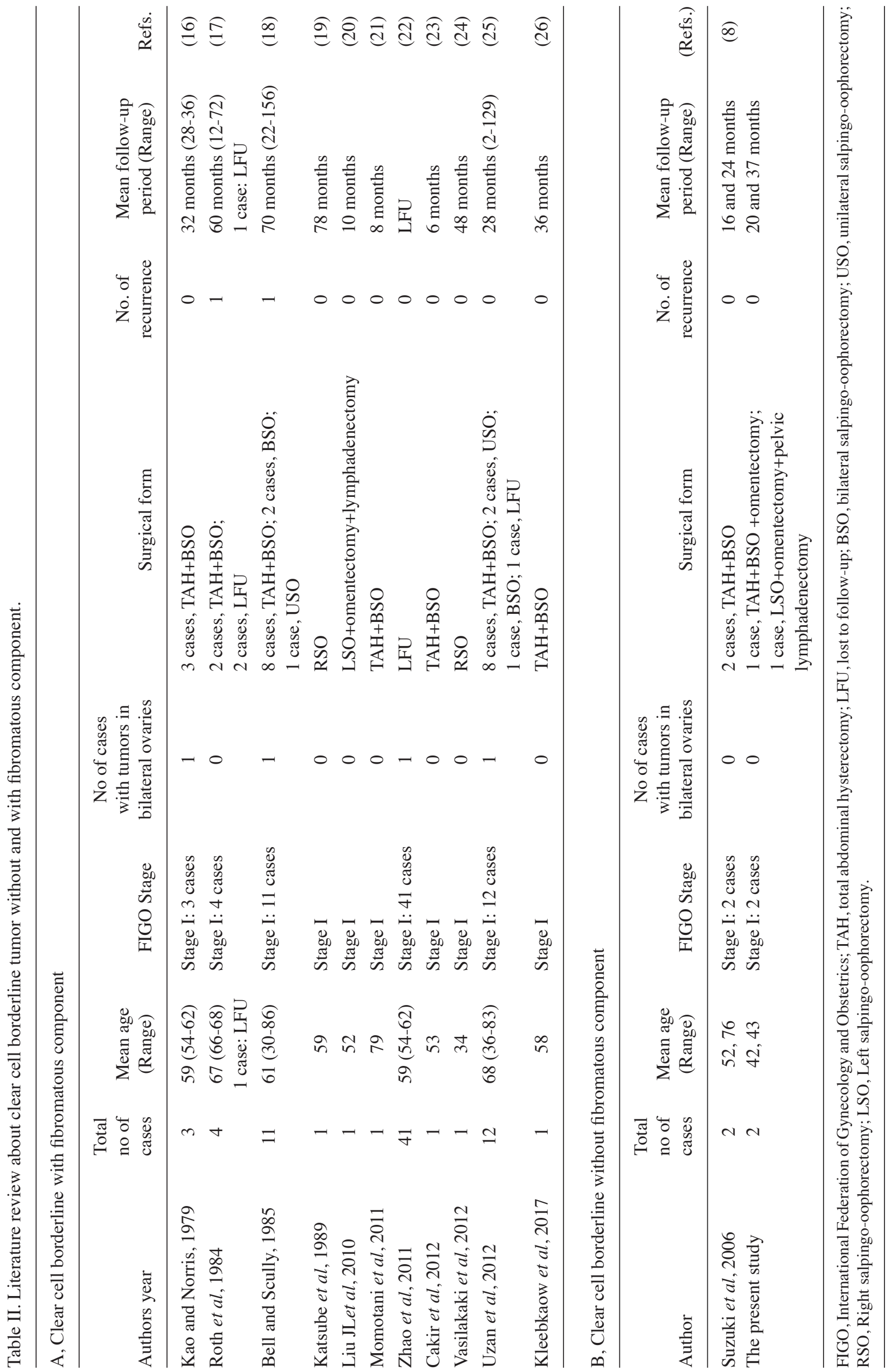


pathway, endometriosis formed an endometriotic cyst, through atypical endometriosis, developed CCC. In the adenofibromatous pathway, endometriosis accompanied by a fibromatous reaction, and subsequently progressed to $\mathrm{CCBT}$ and then to CCC. Thus, CCBT was regarded as deriving from only clear cell adenofibroma in the adenofibromatous pathway. In previous reports, $95.1 \%$ of cases with CCBT coexisted fibromatous component (16-26). However, in case 1 in our case, CCBT was considered to develop from endometriosis because CCBT was adjacent to atypical endometriosis and endometriosis. This finding might indicate the new development of CCBT from endometriosis. Also, 2 cases reported by Suzuki et al. and case 2 in our study, CCBT was without endometriosis and fibromatous component (8). This finding might suggest CCBT derived from neither endometriosis or adenofibroma.

The limitations of this study included a small sample size at a single-institution, and retrospective analysis. Further studies with a large sample size are needed to confirm clinical significance of CCBT without fibromatous component. In addition, our study could not discover the origin except adenofibroma and endometriosis. This problem is the future challenge.

In conclusion, through pathological review, 2 cases of CCBT without fibromatous component was reported. CCBT with fibromatous component was rare and needed to be examined by future study.

\section{Acknowledgements}

The authors would like to thank Mrs. Ayako Suzuki for collecting samples.

\section{Funding}

No funding was received.

\section{Availability of data and materials}

The datasets used and/or analyzed during the current study are available from the corresponding author on reasonable request.

\section{Authors' contributions}

TH designed the study, performed pathological and immunochemical analysis, collected the data and prepared and revised the manuscript. MM designed the study, performed pathological and immunochemical analysis, and prepared and revised the manuscript. HI, HM, TS, SK, HI, and RS collected the data. HT performed pathological and immunochemical analysis. TH and MM confirmed the authenticity of the raw data. MT designed the study, and prepared and revised the manuscript. All authors read and approved the final version of the manuscript.

\section{Ethics approval and consent to participate}

All procedures performed in studies involving human participants were in accordance with the ethical standards of the National Defense Medical Collage hospital and with the 1964 Helsinki declaration and its later amendments or comparable ethical standards. For this type of study formal consent is not required.

\section{Patient consent for publication}

Not applicable.

\section{Competing interests}

All authors declare that they have no competing interests.

\section{References}

1. Taylor HC Jr: Malignant and semimalignant tumors of the ovary. Surg Gynecol 48: 204-230, 1929.

2. Classification and staging of malignant tumours in the female pelvis. Acta Obstet Gynecol Scand 50: 1-7, 1971.

3. Serov SS, Scully RE and Sobin LH (eds); World Health Organization: Histological Typing of Ovarian Tumors. Springer, Berlin, Heidelberg, New York, NY, Geneva, 1973.

4. Silverberg SG, Bell DA, Kurman RJ, Seidman JD, Prat J, Ronnett BM, Copeland L, Silva E, Gorstein F and Young RH: Borderline ovarian tumors: Key points and workshop summary. Hum Pathol 35: 910-917, 2004.

5. Trimble CL, Kosary C and Trimble EL: Long-term survival and patterns of care in women with ovarian tumors of low malignant potential. Gynecol Oncol 86: 34-37, 2002.

6. Lokuhetty D, White VA and Cree IA (eds): WHO Classification of Tumours of Female Reproductive Organs. Lyon, IARC, Lyon, 2020.

7. Seidman JD, Soslow RA, Vang R, Berman JJ, Stoler MH, Sherman ME, Oliva E, Kajdacsy-Balla A, Berman DM and Copeland LJ: Borderline ovarian tumors: Diverse contemporary viewpoints on terminology and diagnostic criteria with illustrative images. Hum Pathol 35: 918-933, 2004.

8. Suzuki A, Shiozawa T, Mori A, Kimura K and Konishi I: Cystic clear cell tumor of borderline malignancy of the ovary lacking fibromatous components: Report of two cases and a possible new histological subtype. Gynecol Oncol 101: 540-544, 2006.

9. Pereira A, Pérez-Medina T, Magrina JF, Magtibay PM, Rodríguez-Tapia A, Peregrin I, Mendizabal Eand Ortiz-Quintana L: International Federation of Gynecology and Obstetrics staging classification for cancer of the ovary, fallopian tube, and peritoneum: Estimation of survival in patients with node-positive epithelial ovarian cancer. Int J Gynecol Cancer 25: 49-54, 2015.

10. Seidman JD, Soslow RA, Vang R, Berman JJ, Stoler MH, Sherman ME, Oliva E, Kajdacsy-Balla A, Berman DM and Copeland LJ: Borderline ovarian tumors: Diverse contemporary viewpoints on terminology and diagnostic criteria with illustrative images. Hum Pathol 35: 918-933, 2004.

11. Hauptmann S, Friedrich K, Redline R and Avril S: Ovarian borderline tumors in the 2014 WHO classification: Evolving concepts and diagnostic criteria. Virchows Arch 470: 125-142, 2017.

12. Ohishi Y, Oda Y, Kurihara S, Kaku T, Yasunaga M, Nishimura I, Okuma E, Kobayashi H, Wake N and Tsuneyoshi M: Hobnail-like cells in serous borderline tumor do not represent concomitant incipient clear cell neoplasms. Hum Pathol 40: 1168-1175, 2009.

13. Ohishi Y, Kurihara S, Aman M, Takeuchi T, Imamura H, Kaku T, Kobayashi H, Wake N and Oda Y: 'Piling up' clear cells in müllerian-type mucinous and mixed cell-type borderline tumor do not represent concomitant clear cell neoplasms. Hum Pathol 43: 1618-1626, 2012.

14. Köbel M, Kalloger SE, Boyd N, McKinney S, Mehl E, Palmer C, Leung S, Bowen NJ, Ionescu DN, Rajput A, et al: Ovarian carcinoma subtypes are different diseases: Implications for biomarker studies. PLoS Med 5: e232, 2008.

15. Kato N, Sasou S and Motoyama T: Expression of hepatocyte nuclear factor-1beta (HNF-1beta) in clear cell tumors and endometriosis of the ovary. Mod Pathol 19: 83-89, 2006.

16. Kao GF and Norris HJ: Unusual cytadenofibromas: Endometrioid, mucinous, and clear cell types. Obstet Gynecol 54: 729-736, 1979.

17. Roth LM, Langley FA, Fox H, Wheeler JE and Czernobilsky B: Ovarian clear cell adenofibromatous tumors. Benign, of low malignant potential, and associated with invasive clear cell carcinoma. Cancer 53: 1156-1163, 1984. 
18. Bell DA and Scully RE: Benign and borderline clear cell adenofibromas of the ovary. Cancer 56: 2922-2931, 1985.

19. Katsube Y, Fujiwara H, Tanioka Y, Imajo M and Fujiwara A: Ovarian clear cell adenofibroma of borderline malignancy. A case report. Hiroshima J Med Sci 38: 87-90, 1989.

20. Liu JL, Chu PY, Yeh KT, Huang RH: Borderline clear cell adenofibroma with extensive hemorrhagic necrosis. Hematol Oncol Stem Ther 3: 158-160, 2010.

21. Momotani K, Tnaka T, Iwai E, Kanda T, Munakata S and Ohmichi M: Ovarian clear cell adenofibromatous tumor of borderline malignancy associated with high levels of carbohydrate antigen 9-9. J Obstet Gynaecol Res 37: 472-477, 2011.

22. Zhao C, Wu LS and Barner R: Pathogenesis of ovarian clear cell adenofibroma, atypical proliferative (borderline) tumor, and carcinoma: Clinicopathologic features of tumors with endometriosis or adenofibromatous components support two related pathways of tumor development. J Cancer 2: 94-103, 2011.
23. Cakir E, Aydin E, Durmus NI, Samdanci E, Sahin N and Nurkabul Z: Primary ovarian clear cell adenofibroma of borderline malignancy. Oman Med J 27: e031, 2012.

24. Vasilakaki T, Skafida E, Arkoumani E, Grammatoglou X, Firfiris N and Manoloudaki K: Borderline clear cell adenofibroma of the ovary associated with ovarian endometriosis: A case report. Eur J Gynarcol Oncol 33: 230-232, 2012.

25. Uzan C, Dufeu-Lefebvre M, Fauvet R, Gouy S, Duvillard P, Darai E and Morice P: Management and prognosis of clear cell borderline ovarian tumor. Int J Gynecol Cancer 22: 993-999, 2012.

26. Kleebkaow P, Aue-Aungkul A, Temtanakitpaisan A and Kietpeerakool C: Borderline clear cell adenofibroma of the ovary. Case Rep Pathol 2017: 3860107, 2017. 